\title{
Pleomorphic sarcoma of the breast
}

Manoj P Rai, ${ }^{1}$ Vinod Kumar Mannelli, ${ }^{1}$ Samanjit Kandola, ${ }^{1}$ Edwin B Marinas ${ }^{2}$

IInternal Medicine, Michigan State University / Sparrow Hospital, Lansing, Michigan, USA

${ }^{2}$ Department of Pathology, Sparrow Hospital, Lansing, Michigan, USA

Correspondence to Dr Manoj P Rai,

manoj.rai@hc.msu.edu

VKM contributed equally.

Accepted 20 October 2017

\section{DESCRIPTION}

This is an 81-year-old man with a history of small bowel carcinoid. He was undergoing routine surveillance (every 6 months) CT chest, abdomen and pelvis with contrast, which showed an incidental left breast mass in the lower inner quadrant, $12 \times 9 \mathrm{~mm}$ concerning for breast neoplasm, there was left axillary lymphadenopathy (LAD) as well (figure 1). Correlation with clinical examination, mammography and ultrasound were recommended. A left breast ultrasound noted a hypoechoic irregular mass with indistinct margins, $7 \mathrm{~mm}$ in size at the 10 o'clock position on the left breast, $3 \mathrm{~cm}$ from the nipple (figure 2). Breast imaging-reporting and data system (BI-RADS) category 4. Bilateral mammogram demonstrated a $1.3 \mathrm{~cm}$ irregular shaped mass at the 10 o'clock position of the left breast. No lymphadenopathy (LAD) was noted on the mammogram or ultrasound. It was categorised as BI-RADS 5 on the mammogram. Bilateral axillary ultrasonography was obtained to evaluate for LAD and biopsy, but no evidence of malignancy was seen and no nodes were deemed necessary for biopsy. He then underwent left breast lumpectomy with histopathology. T1acN0M0, grade 1 , stage IA, $1.3 \times 1.2 \times 1.0 \mathrm{~cm}$ with $0 / 10$ mitoses/hpf. Margins were negative,

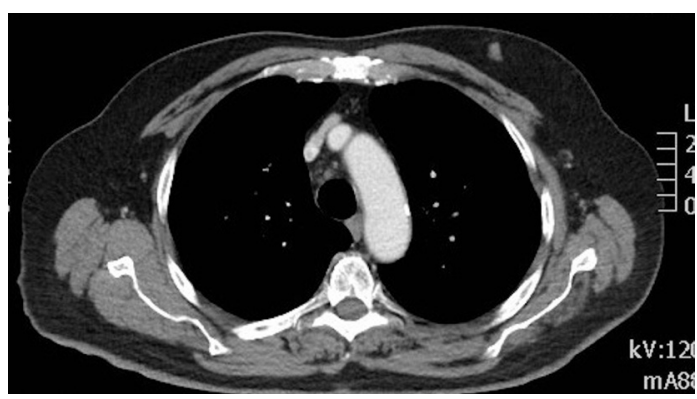

Figure $1 \mathrm{CT}$ of the chest showing an asymmetric left breast mass in the lower inner quadrant, $12 \times 9 \mathrm{~mm}$ with left axillary lymphadenopathy.

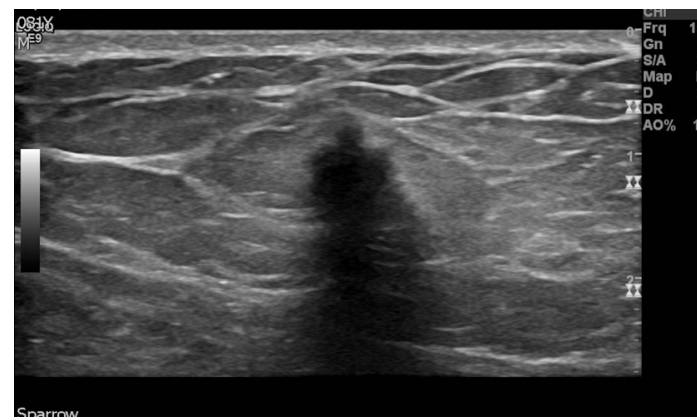

Figure 2 Ultrasound of the breast showing hypoechoic irregular mass with indistinct margins.

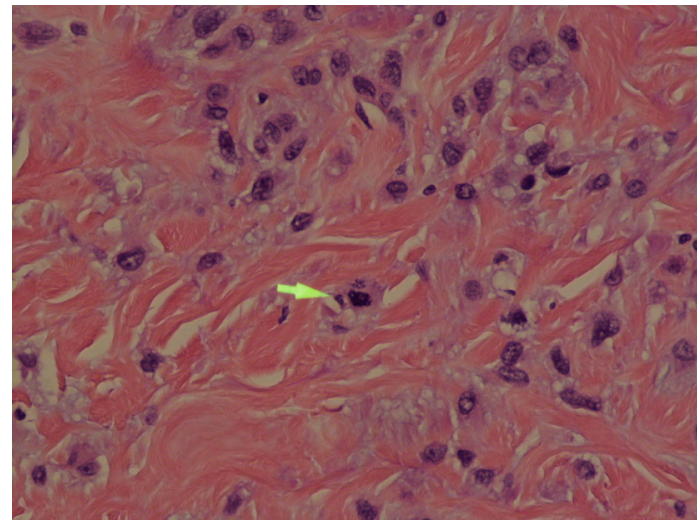

Figure 3 Histopathology—H\&E stain 40x showing mitotic figure.

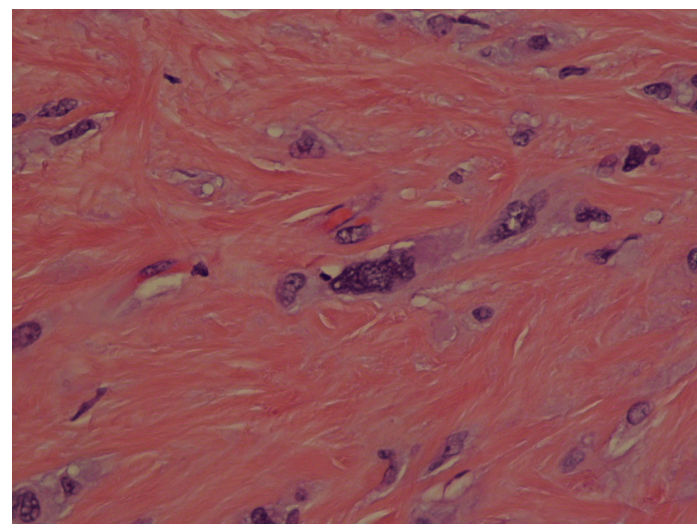

Figure 4 Histopathology—H\&E stain 40x showing pleomorphic nuclei.

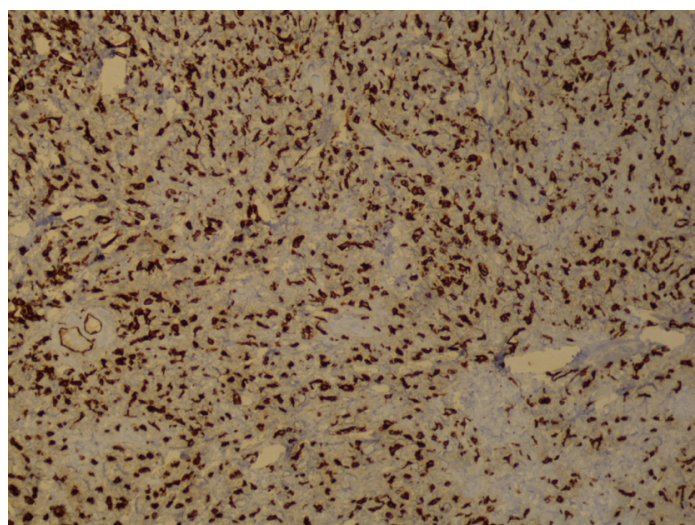

Figure 5 Immunohistochemical staining positive with vimentin.

closest $4-5 \mathrm{~mm}$ anteriorly. Microscopy showed (figures 3 and 4 ) a multinodular appearance, it was composed of pleomorphic polygonal cells with abundant cytoplasm and nuclear pleomorphism 


\section{Learning points}

- Pleomorphic sarcoma of the breast is uncommon, and it is extremely rare in the male population.

- Due to its aggressive behaviour and high rates of recurrence and metastasis, a close follow-up is recommended.

consisting of nuclear enlargement, nuclear multiplication and multinucleation. There was increased cellularity towards the periphery of the nodule. However, there was no significant mitotic activity or necrosis. Morphologically, it was a pleomorphic tumour with extensive hyalinising fibrosis. It was composed of polygonal and epithelial cells with abundant cytoplasm and nuclear pleomorphism including cells with large lobulated nuclei and multinucleation. It appeared to have infiltrative growth pattern at the periphery. The neoplastic cells were diffusely and strongly positive for vimentin with the positive oestrogen and progesterone receptor supporting the diagnosis of pleomorphic sarcoma (figure 5). A diagnosis of low-grade pleomorphic sarcoma (grade 1) was established after getting a second opinion. He is now planned to receive adjuvant radiation therapy. Pleomorphic sarcoma is a rare histologically heterogeneous non-epithelial neoplasm that arises from the mesenchymal tissue within the breast. ${ }^{1}$ It constitutes for less than $5 \%$ of all sarcomas in adults and rarely seen in the breast. It is uncommon in men, mainly seen in women over 64 years of age. Immunohistochemistry is vital to define histogenesis of the lesion and to differentiate undifferentiated carcinoma from mesenchymal neoplasia after the exclusion of epithelial neoplasia. The role of adjuvant treatment with chemotherapy and radiation is unclear. ${ }^{2}$ It is known to have an aggressive clinical course and high rates of recurrence and metastasis. Close follow-up is recommended.

Contributors MPR prepared the manuscript, obtained consent. VKM assisted with literature search. SK assisted with the literature search and writing manuscript. EBM took pictures of the pathology slides and edited the pathology part of the manuscript.

Competing interests None declared.

Patient consent Obtained.

Provenance and peer review Not commissioned; externally peer reviewed.

(c) BMJ Publishing Group Ltd (unless otherwise stated in the text of the article) 2017. All rights reserved. No commercial use is permitted unless otherwise expressly granted.

\section{REFERENCES}

1 Jeong YJ, Oh HK, Bong JG. Undifferentiated pleomorphic sarcoma of the male breast causing diagnostic challenges. J Breast Cancer 2011;14:241-6.

2 Bansal A, Kaur M, Dalal V. Pleomorphic sarcoma of breast: a report of two cases and review of literature. Acta Med Iran 2017;55:272-6.

Copyright 2017 BMJ Publishing Group. All rights reserved. For permission to reuse any of this content visit

http://group.bmj.com/group/rights-licensing/permissions.

BMJ Case Report Fellows may re-use this article for personal use and teaching without any further permission.

Become a Fellow of BMJ Case Reports today and you can:

- Submit as many cases as you like

- Enjoy fast sympathetic peer review and rapid publication of accepted articles

- Access all the published articles

- Re-use any of the published material for personal use and teaching without further permission

For information on Institutional Fellowships contact consortiasales@bmjgroup.com

Visit casereports.bmj.com for more articles like this and to become a Fellow 